\title{
Critiquing a Grounded Theory Research Paper: An Educational Guide for Nurses
}

\author{
Kaba Evridiki ${ }^{1}$, Stavropoulou Areti ${ }^{1}$, Kelesi Martha ${ }^{1}$, Toylia Georgia ${ }^{1} \&$ Fasoi Georgia $^{1}$ \\ ${ }^{1}$ Department of Nursing, School of Health and Care Sciences, University of West Attica, Athens, Greece \\ Correspondence: Kaba Evridiki, Department of Nursing, School of Health and Care Sciences, University of West \\ Attica, Athens, Greece.
}

Received: March 3, 2021 Accepted: April 6, 2021 Online Published: April 13, 2021

doi:10.5539/gjhs.v13n5p92 URL: https://doi.org/10.5539/gjhs.v13n5p92

\begin{abstract}
Critical analysis of research has become a necessary task for nurses who intend to improve the quality of the care they provide by applying robust research evidence to clinical practice. The aims of the present paper are a) to discuss the various stage of critiquing research and $b$ ) to illustrate a case example of research critique by discussing a qualitative research paper. A systematic critique of a grounded theory research article, entitled "How Greek nurses perceive and overcome the barriers in implementing treatment for pressure ulcers: 'Against the odds',', was performed, using a framework that involves all stages needed in critiquing qualitative research. This framework was chosen because it provides specific guidelines and involves a detailed analysis of how each stage of the research must be accomplished.

This critique process led to the development of an educational guide for students and novice researchers, illustrating the methodological approach and the skills needed for conducting a critical analysis of a published qualitative research study.

This paper provides the necessary knowledge to nurse students about how to critique a published research paper and appraise research evidence that guides clinical practice and decision-making for the nursing care delivered.
\end{abstract}

Keywords: research critique, qualitative research, grounded theory, evidence-based nursing, nursing students, nursing education.

\section{Abbreviations: PUs: Pressure Ulcers, GT: Grounded Theory}

\section{Background}

Implementation of research evidence in clinical practice has recently become an imperative task for nurses. Developing proficiency in critiquing research and in applying research evidence into clinical practice is considered to be a basic skill in evidence-based nursing (Polit \& Beck, 2008). Nurses need to be able to understand, synthesize and critique research to support their clinical practice with current best evidence.

A research critique is a systematic assessment of a published paper that involves a thorough analysis of all stages accomplished by using certain criteria. It focuses on the strengths and weaknesses of the research with a specific emphasis on its validity and reliability (Ryan et al., 2007; Polit \& Beck, 2008).

In order to assist nurses to understand how published research can be systematically evaluated, we chose a grounded theory research article as an example to critique and discuss. The reasons for choosing a qualitative research article to criticize are associated with the value of qualitative research, and the knowledge gap that exist in the relevant literature. More specifically, qualitative research is considered one of the most valuable approaches in evidence- based nursing practice, as it explores patients' needs, perceptions and values and enables health care professionals to offer a more personalized care (Addo \& Eboh, 2014; Miller, 2010; Gullick \& West, 2012). In addition, qualitative studies proved to be most appropriate when interventions regarding changes in lifestyle, behaviors, and attitudes are needed.(Houser, 2018; Mantzoukas, 2007; Perry et al., 2011). Despite the fact that many tools have been developed for evaluating qualitative research, there is no relevant published literature, in which, examples of critiquing qualitative research articles are presented (Munthe-Kaas et al., 2019). Furthermore, when nurse researchers wish to successfully implement research evidence in nursing practice, then knowledge education and guidance is needed for both nurse students and nurse professionals. 
This paper attempts to provide an educational guide for nurses on how to critique published research and appraise research evidence that guides clinical practice and decision making for the nursing care delivered. Specifically, the aims of the present paper are a) to explain and discuss various steps of critiquing qualitative research article and b) to illustrate a case example of research critique by discussing a qualitative research article which used a Grounded Theory (GT) approach. The article chosen to be criticized is entitled, How Greek nurses perceive and overcome the barriers in implementing treatment for pressure ulcers: 'Against the odds' was been published in Journal of Wound Care (Kaba et al., 2017). This particular study was chosen as an example to be criticized as it presents a research study which was designed and conducted by the authors of the critique and published in a prestigious peer-reviewed journal. The team's involvement in the conceptualization and design of the abovementioned study consisted an additional motive for selecting this example article to critique. For critiquing this article, a framework developed by Ryan et al. was used (2007).

\section{Methods}

\subsection{The Critiquing Framework}

According to Munthe-Kaas (2019), there are more than 100 tools used for the critical evaluation of qualitative research. It is difficult to decide which critical appraisal tool is the most appropriate since, more or less, the underlying criteria of critiquing qualitative research remain the same.

In this paper, we used a recognized framework developed by Ryan et al. (2007) to demonstrate how to critique a specific research article. This framework was chosen because it provides specific guidelines for critiquing qualitative research, encompasses all the elements influencing believability and robustness of the research and involves an in-depth analysis of how each step of the research must be undertaken (Ryan et al., 2017). The framework divides the critique into two sections:

Section one involves elements influencing the believability of the research, the writing style, the author's qualifications, and the ambiguity of title and abstract.

Section two involves elements influencing the robustness of the research, such as the statement of the phenomenon under investigation, the consistency of the research question and the purpose/significance of the study. Furthermore, in this section, critiquing refers to the literature review, the appropriateness of theoretical framework and philosophical approach used, the sampling strategy, the ethical guidelines, and the process of data collection and analysis. Issues of credibility, dependability, and transferability of the study are also discussed in this section, along with the presentation of findings and discussion. Finally, the importance and implications of the findings and the accurate referencing are appraised.

This framework was applied by the authoring team to critique the qualitative article "How Greek nurses perceive and overcome the barriers in implementing treatment for pressure ulcers: 'Against the odds'” as mentioned above. The steps followed to critique our example grounded theory research paper were explicitly demonstrated in Table 1.

Table 1. Steps followed to critique a grounded theory research paper using the Ryan et al. framework [2].

\begin{tabular}{ll}
\hline Elements of Critique & \multicolumn{1}{c}{ Key Actions to Be Taken } \\
\hline Writing Style & To be evaluated for clarity, accuracy and consistency. \\
\hline Researcher's qualifications & To assure appropriate qualifications and knowledge for examining the research topic. \\
\hline Title & $\begin{array}{l}\text { To be evaluated for clarity, accuracy - it is recommended in GT studies the name of the } \\
\text { core category to be included. }\end{array}$ \\
\hline Abstract & $\begin{array}{l}\text { To be evaluated for clarity in demonstrating the objectives, the method, the results and } \\
\text { the conclusions of the study. }\end{array}$ \\
\hline $\begin{array}{l}\text { Statement of the Phenomenon } \\
\text { under investigation }\end{array}$ & $\begin{array}{l}\text { To be evaluated for clear identification of the phenomenon under investigation - in GT } \\
\text { studies the research question may evolve during the course of the study. }\end{array}$ \\
\hline $\begin{array}{l}\text { Purpose/Significance of the } \\
\text { Study }\end{array}$ & $\begin{array}{l}\text { To be evaluated for clarity and consistency. } \\
\text { To assure that contribution to the existing knowledge was demonstrated. }\end{array}$ \\
\hline Literature Review & $\begin{array}{l}\text { To assure that preliminary literature review was undertaken - in GT studies researcher } \\
\text { needs to avoid preconceived ideas. }\end{array}$ \\
\hline
\end{tabular}




\begin{tabular}{ll}
\hline $\begin{array}{l}\text { Conceptual or theoretical } \\
\text { framework }\end{array}$ & To be evaluated for adequate description, appropriateness and justification. \\
\hline Philosophical approach & $\begin{array}{l}\text { To be evaluated for philosophical justification of the research method. } \\
\text { To assure that the research design and process were discussed and justified appropriately. }\end{array}$ \\
\hline Sample & $\begin{array}{l}\text { To assure that relevant information regarding the sampling strategy, the characteristics of } \\
\text { the sample and the data saturation were explicitly presented. }\end{array}$ \\
\hline Ethical Considerations & $\begin{array}{l}\text { To assure that information about informed consent, moral autonomy and confidentiality } \\
\text { were presented. To assure that participants protected from potential harm and ethical } \\
\text { permission was granted. }\end{array}$ \\
\hline Data Collection/Data Analysis & $\begin{array}{l}\text { To be evaluated for completeness, adequacy of description, appropriateness and } \\
\text { thoroughness. }\end{array}$ \\
\hline Trustworthiness of research & $\begin{array}{l}\text { To assure that credibility, dependability, transferability and confirmability issues were } \\
\text { discussed. }\end{array}$ \\
\hline Findings/Discussion & $\begin{array}{l}\text { To be evaluated for clarity, consistency and accuracy, including appropriate quotations } \\
\text { from the interviews data. To assure that findings were discussed in the context of what is } \\
\text { already known, and limitations were presented. }\end{array}$ \\
\hline References & $\begin{array}{l}\text { To assure that reflect the study's findings and offer recommendations for future research } \\
\text { directions. }\end{array}$ \\
\hline
\end{tabular}

The results of this process are presented and discussed in the following section.

\section{Results and Discussion}

A detailed explanation of how we evaluated our example research article, by using the Ryan et al. critique framework (2007), is provided in this section. Accordingly, the evaluation results of each element of the research are presented and supported by relevant literature.

\subsection{Section One - Elements Influencing the Believability of the Research}

In this first section, of Ryan et al.(2007) critique framework, queries regarding the writing style, the researcher's academic and professional skills and qualifications, the formulation of the title and the abstract, helps thereader to clarify what to expect from the research study and how to ensure the believability of the study (Ryan et al., 2007; Ryan-Wenger, 1992). Questions relating to these elements were applied to our example research article as follows:

\section{Writing Style}

\section{Is the report well written - concise, grammatically correct, avoids the use of jargon? Is it well laid out and organized?}

To assure that the phenomenon under investigation "How Greek nurses perceive and overcome the barriers in implementing treatment for pressure ulcers: 'Against the odds" " was explained in a clear and detailed way, our example research article was checked for clarity and consistency. We found that jargon was kept to a minimum, grammar was checked for accuracy and appropriate headings were used to clearly define the different sections laid in the article. Also all the criteria and principles on composing and evaluating a good qualitative research study were used, based on the concrete advice for writing and publishing a qualitative scientific article by Stenius et al. (2017).

\section{Author}

\section{Do the researcher's qualifications/position indicate a degree of knowledge in this particular field?}

The authors' main concern before the commencement of the critiquing study was to formulate a research team which holds the appropriate qualifications and knowledge for examining the research topic. For this purpose, a research team was developed involving academics and nursing scientists, specialized in areas such as qualitative research, treatment and care of wounds and ulcers, quality of care and assessment of educational interventions. This multidisciplinary profile of the research team offered expertise and credibility to the research study by ensuring appropriate knowledge and experience in the field. 


\section{Title}

\section{Is the title clear, accurate and unambiguous?}

The title of our example article, "How Greek nurses perceive and overcome the barriers in implementing treatment for pressure ulcers: 'Against the odds", was checked for clarity and accuracy. According to Stenius et al., (2017) a title that clearly shows the area the authors are interested in will attract more readers and consequently more citations for the paper.

In the same vein, Bavdekar (2016) stated that the title should be written in such a way that readers will understand it and then decide if the paper is interesting to them or not. It should be also in accordance to study aims and questions (Drisko, 2005). Authors should always try to choose an informative, appropriate and catchy title for their research study. A title can be made attractive either by using a famous quote in the title, or by creating probably a new acronym. Generally, it must contain 10-15 words. When the title is too lengthy may divert readers' attention and make them feel bored. On the contrary, when the title is too short, it may fail to provide readers with the appropriate information needed about the article content. As Polit and Beck (2008) state, the title of qualitative studies usually states the central phenomenon under investigation. GT studies often contain something from the findings in the title, for example, the core category or a representative phrase of a quotation. Following this idea the title in our example article included the core category namely 'against the odds' that indicates how the perceived value of prevention and treatment can overcome the barriers in treating pressure ulcers (PUs).

\section{Abstract \\ Does the abstract offer a clear overview of the study, including the research problem, sample, methodology, findings and recommendations?}

The structure and length of the abstract usually is guided by each journal's instructions to authors. In our example article, the abstract was written according to the Journal of Wound Care instruction and it was carefully patterned for clearly demonstrating the objectives, the method, the results and the conclusions of the study, as presented below:

"Objective: Although the occurrence of pressure ulcers (PUS) is now considered as an indicator of poor-quality nursing care, questions and concerns remain regarding situations where PUs were unavoidable, irrespective of the care provided. The aim of this study was to. Method: A grounded theory approach was used and semi-structured interviews were conducted with nurses who provided pressure care to clients in a rehabilitation center in Greece. Data were analyzed using the constant comparative method. Results: We interviewed seven nurses. Findings revealed one main category entitled 'anarchy' in delivery of care consisted of the following three subcategories: interdisciplinary conflicts; total trust in traditional knowledge; and devaluation of other's work/role and a core category 'Against the odds': the perceived value of prevention and treatment can overcome the barriers in treating PUs. Conclusion: This study gives an overview of the views and beliefs of nurses about the problems and barriers involved in PU prevention and treatment. The study reveals that although some barriers to good practice may exist, nurses can hold a positive attitude toward PU prevention and treatment, and their perceived value of prevention and treatment may help nurses to overcome the barriers in managing PUs".

The abstract of a qualitative paper is usually a short summary of the research report (Polit \& Hungler, 2013; Borbasi, 2012; Nieswiadomy, 2012). It should include some information about the aim and the background of the study as well as the methods of data collection and analysis, results and conclusions. The abstract in qualitative studies is written in a more narrative way and less formal in comparison with the abstract in quantitative studies (Borbasi, 2012).

\subsection{Section Two - Elements Influencing the Robustness of the Research}

In the second section of Ryan et al.'s (2007) critique framework, queries regarding the strengths of the research and its related elements may help the reader to synthesize a concise and integrated view about the quality of the study.

\section{Statement of the Phenomenon of Interest}

Is the phenomenon to be studied clearly identified? Are the phenomena of interest and the research question consistent?

In our example article, the phenomenon studied was identified as being "the nurses'perceptions about the barriers in implementing treatment for leg ulcers". It was further justified that "although the occurrence of pressure ulcers $(P U s)$ is now considered as an indicator of poor quality nursing care, questions and concerns remain regarding situations where PUs were unavoidable, irrespective of the care provided." (Kaba et al., 2017). 
In our example article, the research question, was not clearly stated. However, as Streubert and Carpenter (2011) argued, usually the aim of the qualitative research is to explore ideas, and the researcher does not need to have a predetermined research question at the beginning of the study. Even more, Houser (2018) advocated that the research questions, in a qualitative study, arise, evolve and change during the course of the study. In addition, GT studies are rarely undertaken to answer a central research question (Fain, 2014). As the purpose of such a research is to develop theory, the GT study proceeds from a broad area of interest to discover how individuals react and interact with each other, how they experience a problem, what are their main concerns and how they cope with these concerns (Hernandez, 2010).

\section{Purpose/Significance of the Study}

\section{Is the purpose of the study/research question clearly identified?}

The aims of our example article were explicitly reviewed for clarity and consistency. The authors justified the significance of the study and the expected benefits. This is in accordance with what Connell (1999) stated, that the researchers need to explain the implications of the study and how it will add to the existing body of knowledge. The researchers should always provide a concrete justification of why they will use the specific qualitative methodology (1999). However, the authors of the critiquing paper could have added benefit to the paper by providing a more explicit justification of why they chose a qualitative approach, particularly the GT methodology used to investigate this area. For example, to explain that qualitative research methods including GT attract nurses for several reasons, as they assists them to gain new knowledge and improve their practice in a more meaningful way (Hammarberg et al., 2016; Nathaniel \& Andrews; 2007). Furthermore, that GT is useful for investigating areas where there are major gaps in understanding, when little is known about a phenomenon and where a new standpoint might be needed (Schreiber, 2001). Studies using GT methodology can generate new nursing knowledge derived from real interactions with patients as well as by interpreting how participants make sense of their perceptions and actions (Charmaz, 2014).

\section{Literature Review}

Has a literature review been undertaken? Does it meet the philosophical underpinnings of the study? Does the review of the literature fulfil its objectives?

A preliminary literature review was undertaken in our example GT study. This was consistent with Hallberg's (2010) idea that an early literature review is necessary in order to check if a similar study with the proposed one has already published. The reason that the literature review was only preliminary, is in line with the view of Glaser (1998) who supports the necessity for GT-researchers to do some preliminary literature review before the commencement of the research in order to put the study into a context. As Hussein (2017) stated, the literature review in GT, should be a multistage, nonlinear approach to the literature. In the first stage, researchers identify gaps in existing research in the field, and explain the reasons for doing the research study. Further to this, Barney Glaser (1998), the originator GT methodology, stated that the GT researcher needs to avoid preconceived ideas and remain open to new ideas that will appear in the research field. Glaser (1998) also believed that an early conducting of the literature review, before the study begins, will be problematic. However, it is difficult to find a researcher who conceptualizes new meanings and notions without having read the professional and disciplinary literature. The researcher cannot put this knowledge and his/her perspectives aside when starting a new study, but can try not to be consciously directed by earlier theories and notions when trying to interpret the data. The golden rule for the GT researcher is to avoid an extensive literature review before the study begins, but on the other hand to be informed enough and focused on the study (Hallberg, 2010; Glaser \& Strauss, 1967).

\section{Has a conceptual or theoretical framework been identified? Is the framework adequately described? Is the framework appropriate?}

As previously stated, the conceptual/theoretical framework used in our example research study was GT. The steps followed were adequately described by the authors. A more detailed explanation, however, of what GT is and why it is used in this study would be beneficial for the overall quality of the paper. For example, mentioning that GT is a method used to collect and analyze qualitative data that aims to develop theories and theoretical considerations grounded in real world observations would have been appropriate (Polit \& Beck, 2006). It would be also beneficial to mention that GT is considered the appropriate research approach in areas where major gaps in the literature exist and where new perspectives might be needed (Schreiber, 2001). In GT studies, the researcher begins to develop an understanding of participants' experiences, interpreting their perceptions and actions (Charmaz, 2014). The researcher needs to mention this, in the study, and explain that this research approach was chosen because there is not enough information about the phenomenon under study, or the existing theories cannot answer the research 
problem (Cronin \& Rawlings-Anderson, 2003). Although a theoretical framework is the paramount objective for most qualitative approaches, it is not necessary for GT studies. The aim of GT research is not to test an existing theory but to generate theory from real-world data, (Strauss \& Corbin, 1990).

Has the philosophical approach been identified? Why was this approach chosen? Has the philosophical underpinnings of the research been explained?

Symbolic Interactionism (SI) is the philosophical approach that is historically linked to GT (Charmaz, 2006). As GT research aims to explain social processes and develop substantive or formal theory (Bernard, 2002; Morse, 1995), the goal of Symbolic Interactionism (SI) tradition is to understand "the complex world of lived experience from the point of view of those who live it (Beauchamp, 2001). An additional advantage for our example research paper would be if the authors had specified that their research design was driven by SI, the philosophical premise of GT (Charmaz, 2006). Despite the lack of a thorough philosophical justification of the research method, the research design and process were discussed and justified appropriately throughout our example article.

\section{Sample}

Is the sampling method and sampling size identified? Is the sampling method appropriate? Were the participants suitable for informing research?

In our example research study, the authors declared that;

"A purposeful sample of seven participants was selected. All were nurses working in a public rehabilitation center in an urban area in Athens, Greece" (Kaba et al., 2017).

An issue that might be raised here, is that the authors described their sample as "purposeful" by failing to refer to "theoretical sampling" which is fundamental in every GT study. By mentioning the purposeful sample the authors intended to emphasize the initial sampling strategy, as the participants who were recruited had appropriate knowledge and experience in the field under investigation (PUs). However, theoretical sampling, in our example research study, occurred as the data collection progressed. This was demonstrated in relevant sections of our GT research article. In GT studies, the researcher initially identifies a small number of participants to interview who have experienced the phenomenon under study and are able to talk about their experiences in a clear, expressive, and thoughtful way (Bernard, 2002). As the interviews and the analysis proceed, the codes and categories developed from the first data set, will guide the theoretical sampling. Depending on the results from the first round of data analysis, the researcher may recruit more participants, to interview, who will confirm or disagree with what the researcher has already found. The process of theoretical sampling stops when data saturation is achieved and when no new information emerges from data analysis (Morse, 1995). The authors in the example article, provided all relevant information regarding the sampling strategy and the data saturation. Specifically, they mentioned that,

"data collection continued until 'theoretical saturation' was achieved, whereby no new or relevant insights seemed to be emerging from the data being collected and when no further information, themes or ideas were forthcoming"

A more explicit description to participants' characteristics and inclusion criteria would be beneficial for our example article. It is to the study's benefit that the researcher explicitly describes the characteristics of the sample. An extensive description of the sample gives the reader the information needed in order to be able to judge the transferability of the findings to other settings and patients (Houser, 2018).

\section{Ethical Considerations}

Were the participants fully informed about the nature of the research? Was the autonomy/confidentiality of the participants guaranteed? Were the participants protected from harm? Was ethical permission granted for the study?

Most of the above mentioned questions were addressed in our example research paper. Authors specifically stated,

"Ethical approval was sought and granted by the research and ethics committee of the rehabilitation center. Participation was voluntary and anonymity of the nurses was ensured. All participants received a statement both verbally and written of what the research involved, the aims and the procedures of the project, and the participants' commitments as they had the right to full disclosure' (Kaba et al., 2017).

Referring to a signed informed consent form would be an additional merit for the quality of the critiquing article. In every research study, participants should always have the right to give informed consent regarding their participation and also have the right to withdraw from the study at any time. This means that participants should be fully informed about the aim of the study, what sort of information will be collected, how this information will be used and if there are any implications for them as participants in the study. This moral principle is known as 
autonomy (Beauchamp, 2001). According to Ryan et al. (2007), in qualitative research, when vulnerable populations are recruited in the study, it is crucial for the researcher to make sure that their rights are protected.

Approval from ethical committees or institutional review boards are necessary before the research begins. The purpose is to determine that the study adheres to the ethical principles and that participants are protected from potential harm (Burns \& Grove, 2001). It should be mentioned that, in qualitative research, ethical issues may emerge at every stage in the study and should be discussed when they occur.

In qualitative interviews, participants are encouraged to 'open up' and discuss their experiences. This means that participants can unintentionally discuss personal matters or uncomfortable experiences that they had not intended to uncover. The participants can communicate to reveal whether they are comfortable continuing with the interview or would prefer to discontinue their participation (Polit \& Beck, 2006). However, discontinuing participation alone can be insufficient to meet the principle of non-maleficence (doing no harm), so psychological support should be offered to help the participant cope with any emotional distress caused by the interview (Smith, 1992).

\section{Data Collection/Data Analysis}

Are the data collection strategies described? Are the strategies used to analyze the data described? Did the researcher follow the steps of data analysis method identified? Was data saturation achieved?

Data collection process and strategies were carefully evaluated in our example article by the authoring team for completeness and adequacy of description. The authors mentioned that,

"Data were collected by audio-taped interviews using open-ended questions, skilled observation and documentation. During the interview process, participants were asked to share their perceptions of the barriers involved in PU prevention and treatment. Data gathering involved asking the participants to describe what they do for the management of PUs and how they believe that care should be delivered. Other areas were explored as they arose, for example, when participants talked about why they were unable to provide quality care, the reasons why they believed this to be the case and any barriers involved were examined." (Kaba et al., 2017)

This is in accordance with GT approach, in which the initial opening question of the unstructured interview should be presented and clearly linked to the purpose of the study (Ryan, 2007). The authors also stated that they used the process of constant comparative analysis until data saturation was reached, according to the GT principles (Strauss \& Corbin, 1998). Specifically, in our example research article, the process of data analysis was clearly presented and justified:

"An ongoing and simultaneous collection and analysis of the data led to the formulation of hypotheses and guided further data collection. The constant comparative method was used in data collection and analysis. Constant comparative analysis involves relating data to ideas, then ideas to other ideas. This is done through 'coding' the data. Data collection continued until 'theoretical saturation' was achieved, whereby no new or relevant insights seemed to be emerging from the data being collected and when no further information, themes or ideas were forthcoming. The constant comparative method together with theoretical sampling constitute the core of qualitative analysis in the grounded theory approach (Glaser \& Strauss, 1967). The method of comparing and contrasting is used for practically all intellectual tasks during analysis: forming categories, establishing the boundaries of the categories, assigning the segments to categories, summarizing the content of each category and finding negative evidence. The interviews were analyzed word by word, line by line, and sentence by sentence. Codes were allocated for each word or phrase and labels were given to emerging themes and then coded. Codes were then sorted into categories and redefined into further categories. Then the core category had been identified and other connected categories, properties and connections between categories". (Kaba et al., 2017)

The presentation of a framework or a table, explaining the coding process, would significantly add to the value of our example GT study. This is supported by Ryan et al. (2007), who suggested that the researcher in a GT study should present how the concurrent data collection, analysis and coding were performed.

Does the research discuss how rigor was assured? Were credibility, dependability, transferability and goodness discussed?

According to Houser (2018), in qualitative research, the purpose is to interpret a phenomenon, rather than to test a hypothesis. Generalization of the results is not its intention. Internal and external validity is not a concern in qualitative research. Qualitative researchers are concerned with representing real-world phenomena in an accurate way and eliminating bias in researchers' interpretations (Glaser \& Strauss, 1967). There is a strong and ongoing debate, between qualitative researchers, about the concepts of validity and reliability in qualitative research. Some 
believe that the philosophy of qualitative research opposes to the notion of validity, whereas others argue that efforts to produce validity enhance the credibility of the findings (Koch \& Harrington, 1998; Tobin \& Begley, 2004; Hoye \& Severinsson, 2007). The challenge, in qualitative research, is to produce reliable and credible evidence that demonstrates rigor and integrity of the research process (Ryan et al., 2007; Koch, 2006). The seminal work of Guba and Lincoln (1989) proposed the idea that qualitative research is based on trustworthiness rather than reliability and validity. The most common categories of quality criteria, applied to assess the key elements of trustworthiness, are credibility, dependability, transferability and confirmability (Schou et al., 2012; Lincoln \& Guba, 1985).

In our example research article, we did not use specific tools or frameworks to appraise the trustworthiness of the study. However, the authors discussed how they ensured the trustworthiness of their study. For example, regarding credibility, it was stated that,

"In order to improve the credibility and establish the trustworthiness the researcher had prolonged engagement by investing sufficient time in the data collection activities to learn the culture of the group under study, to test for misinformation and distortions, and to build trust with informants. For this purpose the researcher-interviewer in this study was involved in the area of investigation long before the data collection commencement; by visiting the rehabilitation center, being introduced to nurses and talking to them. Most participants had been introduced to the interviewer long before the interview and this added familiarity to the interview atmosphere as participants felt comfortable and seemed to trust the interviewer" (Kaba et al., 2017).

Relevant literature stresses that credibility exists when there is a consistency between the participants' views and the researchers' representation of them. When the researcher describes and interprets his/her experiences, and gives the participants to read and discuss the research results, credibility can be enhanced. Credibility can be achieved by prolonged engagement, observation and audit trails (Bekhet \& Zauszniewski, 2012). Furthermore, analyst triangulation, an additional method of ensuring trustworthiness in qualitative research, was mentioned in our example article:

"Continued improvements, including rereading the transcripts, redrawing the concepts and the categories, and reviewing the literature completed the process of analysis. To test the consistency in open coding of the researcher, a second researcher also coded all the interviews" (Kaba et al., 2017).

Triangulation is a common method that qualitative researchers use to establish trustworthiness of research. Credibility of the results can be enhanced when the researcher use multiple researchers to cross-check the results and the researcher's interpretations (Korstjens \& Moser, 2018). In most qualitative studies, trustworthiness is confirmed by applying selected strategies such as audit trails, detailed description of sample and setting, data triangulation and peer checking, participant feedback or member checking, reflexivity, or bracketing the researcher's bias. These strategies of ensuring trustworthiness enable the researchers to support the validity and usefulness of their findings and to promote dependability, transferability and confirmability of research (Houser, 2018; Korstjens \& Moser, 2018).

\section{Findings/Discussion}

Are the findings presented appropriately? Has the report been placed in the context of what was already known of the phenomenon? Has the original purpose for the study been adequately addressed?

The findings in our example research article were presented in a consistent way, including appropriate quotations from the interviews data and providing thus evidence for relevant interpretations. Houser (2018) stated that qualitative researchers should avoid making inferences by carefully keeping accurate field notes and reporting the results as accurate quotes. Descriptions should use the participants' words. This accurate reporting ensures that the content, that is given, is the participant's view and not the researcher's interpretation of it. A popular way to illustrate and support the themes derived from the data, is to use "low-inference descriptors", that is, examples of participants' verbatim accounts. Integrating quotations from participants, when writing the findings, demonstrates that the report is grounded in the data.

All the categories in our example article were presented focusing specifically on the core category of "against the odds", and the authors showed how the categories of their analysis were related:

"The results of the analysis showed that the perceived problems of the interviewees with regard to PU treatment and the barriers in delivery of efficient health care could be categorized into one main category entitled 'anarchy' in delivery of care followed by three subcategories: interdisciplinary conflicts; total trust in traditional knowledge, devaluation of other's work/role. Further analysis lead to the formulation of a core category namely 'against the odds': the perceived value of prevention and treatment can overcome the barriers in treating PUs. 'Anarchy' in 
delivery of care consisted of the subcategories that constitute the problems and the barriers involved in delivery of best practice and efficient health care.

Nurses interviewed managed to beat all the problems and barriers caused by the 'anarchy' in delivery of care and the PUs tend to have a good outcome. Their perceived value of prevention and treatment can overcome the barriers in treating PUs. A positive attitude towards prevention and awareness about the significance of the problem are the basis to effective prevention. These positive views and beliefs can be used as a starting point for effective implementation of guidelines regarding the treatment of Pus" (Kaba et al., 2017).

The aims of the study have been adequately addressed and the authors discussed the findings in the context of what is already known by reviewing the relevant literature. However, at this point a limitation was recognized by the authors recognized since, "this was one of few studies conducted on nurses' perceptions of prevention and treatment of PUs in Greece, thus there is not enough literature available to discuss in national context (Kaba et al., 2017).

Further limitations were also discussed, such as the restricted number of participants and the lack of triangulation of the qualitative data with other quantitative data.

\section{Conclusion/Implications and Recommendations}

Are the importance and implications of the findings identified? Are recommendations made to suggest how the research findings can be developed?

In our example article, the significance and implications of the findings were identified, and recommendations of how these findings can be developed, were made. According to Ryan et al. (2017), the researcher should write the findings in such a way that readers will accept its implications to nursing practice. The conclusions of the study should reflect the study's findings and should offer recommendations for future research. Accordingly, in our example research article, the authors presented the recommendations and implications to practice of their study:

"This study reveals that although some barriers to good practice may exist, nurses can hold a positive attitude toward PU prevention and treatment. Positive attitude is the paramount leader in preventing PU. The attitude could constitute a milestone for enhancing practice in PU prevention and treatment. Understanding the value that nurses place on PU prevention and treatment and given that education has been shown to change a person's values, a program of education can be established for nurses to ensure that they place an appropriate value on $P U$ prevention and deliver a high standard of skin care to their patients. Future research must focus on nurses' education about the roles and responsibilities regarding the maintenance of skin integrity in clinical practice and raising awareness of $P U$ preventive and treatment interventions. Also more research is needed to focus on the adequate dissemination of prevention and treatment guidelines".

This final part of the study is usually an effort explain the results. It includes an interpretation of the results, the study limitations and possible implications for future research to raise new knowledge on the phenomenon under study (Polit \& Hungler, 2013). The conclusions may be very broad, purely highlighting an issue by raising awareness or further understanding of a human experience. The research study should persuade the readers of the research, such as nurses, that the findings of the qualitative research are credible and trustworthy (Borbasi, 2012).

\section{References}

\section{Were all the books, journals and other media alluded to in the study accurately referenced?}

References were checked for accuracy. Scientific writing requires an accurate list of all bibliographic sources that were included in the study (Polit \& Beck, 2003). A meticulous engagement of the researchers with the reference listing demonstrates soundness and rigor of the research study. In addition, an explicit and scholarly cited reference list may provide an important source for further reading for those who are interested in the specific research topic (Ryan et al., 2017).

\section{Conclusions}

Within the frame of a critical analysis of the grounded theory research article, entitled "How Greek nurses perceive and overcome the barriers in implementing treatment for pressure ulcers: 'Against the odds',", we aimed to offer the necessary knowledge to nursing students and nurse professionals to critically review qualitative research literature by explicitly explaining how each step of a qualitative research is undertaken. Informing student nurses and novice researchers about how to critique qualitative research, in an organized and systematic manner by providing a real example, is one of the strengths of the present paper. Furthermore, this critique study served as an in-depth critical analysis of the authors' work that enhanced evaluative and critical thinking skills. That was a challenging issue which enabled further understanding of research critique through disciplinary teamwork. The 
most important benefit, however, was that the authors had to reflect on their own work, not only from the teachers', but also from the students' point of view in order to achieve a successful outcome. At the same time, that was one of the difficulties faced throughout the course of critiquing the research article. In addition, the inherent subjectivity of qualitative research, and its holistic and unique nature that makes it difficult to critique, consist an additional limitation in this paper. Despite that, nursing students and young researchers must be able to determine the strengths and limitations of studies when reviewing the available literature on a topic, thus justifying clinical decision making with best research evidence.

\section{Competing Interests Statement}

The authors declare that there are no competing or potential conflicts of interest.

\section{References}

Addo, M., \& Eboh, W. (2014) Qualitative and quantitative approaches. In R. Taylor (Ed.), The Essentials of Nursing and Healthcare Research (pp.137-154). London: Sage Publications Limited.

Bavdekar, S. B. (2016). Enhance the value of a research paper: Choosing the right references and writing them accurately. Journal of the Association of Physicians of India, 64, 66-70.

Beauchamp, T., \& Childress, J. (2001). Principles of Biomedical Ethic (5th ed., p.454). Oxford, US: Oxford University Press.

Bekhet, A. K., \& Zauszniewski, J. A. (2012). Methodological triangulation: An approach to understanding data. Nurse researche, 20, 40-43. https://doi.org/10.7748/nr2012.11.20.2.40.c9442

Bernard, H. R. (2017). Research methods in anthropology: Qualitative and quantitative approaches (3rd ed., p. 584 p.). Rowman \& Littlefield.

Borbasi, S., Jackson, D., \& East, L. (2012). Navigating the Maze of Research (3rd ed., p. 730). Sydney, AUS: Mosby Elsevier, Chatswood.

Burns, N., \& Grove, S. (2001). The Practice of Nursing Research: Conduct, Critique and Utilization (p.736). Philadelphia, US: WB Saunders.

Charmaz, K. (2006). Constructing grounded theory: A practical guide through qualitative analysis (p. 192). London, UK: Sage Publications.

Charmaz, K. (2014). Constructing grounded theory (2nd ed., p. 416). London, UK: Sage Publications.

Connel, M. T. (1999). The research critique in Nursing Research and Design (P. H., Tracy, Ed., p. 57-74). Dublin: UCD Press.

Cronin, P., \& Rawlings-Anderson, K. (2003). Knowledge for Contemporary Nursing Practice (p. 200). Edinburgh, UK: Mosby.

Drisko, J. (2005). Writing up qualitative research. Families in Society. The Journal of Contemporary Social Services, 86, 589-593. https://doi.org/10.1606/1044-3894.3465

Fain, J. (2014). Reading, understanding, and applying nursing research (4th ed., p. 392). Philadelphia, US: PA: F. A. Davis.

Glaser, B., \& Strauss, A. (1967). The Discovery of Grounded Theory: Strategies for Qualitative Research (p. 282). Mill Valley, CA, US: Sociology Press.

Glaser, B., \& Strauss, A. (1967). The Discovery of Grounded Theory: Strategies for Qualitative Research (p. 271). New Brunswick, USA \& London, UK: Aldine Transaction.

Glaser, B. (1998). Doing Grounded Theory: Issues and Discussions (p. 254). Mill Valley, CA, US: Sociology Press.

Guba, E. G., \& Lincoln, Y. S. (1989). Fourth generation evaluation (p. 294). CA, UK: Sage Newbury Park.

Gullick, J., \& West, S. (2012). Uncovering the common ground in qualitative inquiry: Combining quality improvement and phenomenology in clinical nursing research. International journal of health care quality assurance, 25(6), 532-548. https://doi.org/10.1108/09526861211246485

Hallberg, L. R. (2010). Some thoughts about the literature review in grounded theory studies. Int J Qual Stud Health Well-being, 5, 102. https://doi.org/10.3402/qhw.v5i3.5387

Hammarberg, K., Kirkman, M., \& de Lacey, S. (2016). Qualitative research methods: when to use them and how to 
judge them. Human reproduction, 31(3), 498-501. https://doi.org/10.1093/humrep/dev334

Hernandez, C. A. (2010). Getting grounded: Using Glaserian grounded theory to conduct nursing research. Canadian Journal of Nursing Research Archive, 150-164.

Houser, J. (2018). Nursing Research: Reading, Using and Creating Evidence: Reading, Using and Creating Evidence (4th ed., p. 500). MA, UK: Jones \& Bartlett Learning.

Høye, S., \& Severinsson, E. (2007). Methodological aspects of rigor in qualitative nursing research on families involved in intensive care units: a literature review. Nursing \& health sciences, 9(1), 61-68. https://doi.org/10.1111/j.1442-2018.2007.00300.x

El Hussein, M. T., Kennedy, A., \& Oliver, B. (2017). Grounded theory and the conundrum of literature review: Framework for novice researchers. The Qualitative Report, 22(4), 1199.

Kaba, E., Kelesi, M., Stavropoulou, A., Moustakas, D., \& Fasoi, G. (2017). How Greek nurses perceive and overcome the barriers in implementing treatment for pressure ulcers:'against the odds'. Journal of wound care, 26(Sup9), S20-S26. https://doi.org/10.12968/jowc.2017.26.Sup9.S20

Koch, T., \& Harrington, A. (1998). Reconceptualizing rigour: the case for reflexivity. Journal of advanced nursing, 28(4), 882-890. https://doi.org/10.1046/j.1365-2648.1998.00725.x

Koch, T. (2006). Establishing rigour in qualitative research: the decision trail. Journal of advanced nursing, 53, 91-100. https://doi.org/10.1111/j.1365-2648.2006.03681.x

Korstjens, I., \& Moser, A. (2018). Series: Practical guidance to qualitative research. Part 4: Trustworthiness and publishing. European Journal of General Practice, 24(1), 120-124. https://doi.org/10.1080/13814788.2017.1375092

Lincoln, Y. S., \& Guba, E. G. (1985). Naturalistic inquiry (vol. 75, p. 416). Thousand Oaks, CA, US: Sage.

Mantzoukas, S. (2007). Qualitative research in six easy steps: the epistemology, the methods and the presentation. Nursing (Greek journal), 46, 88-98.

Miller, W. R. (2010). Qualitative research findings as evidence: utility in nursing practice. Clinical nurse specialist CNS, 24(4), 191. https://doi.org/10.1097/NUR.0b013e3181e36087

Morse, J. M. (1995). The significance of saturation. Qual Health Res., 5, 147-149. https://doi.org/10.1177/104973239500500201

Munthe-Kaas, H. M., Glenton, C., Booth, A., Noyes, J., \& Lewin, S. (2019). Systematic mapping of existing tools to appraise methodological strengths and limitations of qualitative research: First stage in the development of the CAMELOT tool. BMC medical research methodology, 19(1), 1-13. https://doi.org/10.1186/s12874-019-0728-6

Nathaniel, A. K., \& Andrews, T. (2007). How grounded theory can improve nursing care quality. Journal of Nursing Care Quality, 22(4), 350-357. https://doi.org/10.1097/01.NCQ.0000290417.27393.91

Nieswiadomy, R. M. (2012). Foundations of Nursing Research (p. 432). Boston, US: Pearson.

Perry, L., Bellchambers, H., Howie, A., Moxey, A., Parkinson, L., Capra, S., \& Byles, J. (2011). Examination of the utility of the promoting action on research implementation in health services framework for implementation of evidence based practice in residential aged care settings. Journal of Advanced Nursing, 67(10), 2139-2150. https://doi.org/10.1111/j.1365-2648.2011.05655.x

Polit, D., \& Beck, C. (2006). Essentials of Nursing Research: Methods, Appraisal and Utilization (6th ed., p. 554). Philadelphia, US: Lippincott Williams \& Wilkins.

Polit, D. F., \& Hungler, B. P. (2008). Essentials of Nursing Research: Methods, Appraisal, and Utilization (8th ed., p. 253). Philadelphia, US: Lippincott Williams \& Wilkins.

Polit, D. F., \& Beck, C. T. (2008). Nursing research: Generating and assessing evidence for nursing practice (8th ed., pp. 105-138). Philadelphia, US: Lippincott Williams \& Wilkins.

Ryan, F., Coughlan, M., \& Cronin, P. (2007). Step-by-step guide to critiquing research. Part 2: Qualitative research. British journal of nursing, 16(12), 738-744. https://doi.org/10.12968/bjon.2007.16.12.23726

Ryan-Wenger, N. M. (1992). Guidelines for critique of a research report. Heart \& lung: the journal of critical care, 21(4), 394-401.

Schou, L., Høstrup, H., Lyngsø, E. E., Larsen, S., \& Poulsen, I. (2012). Validation of a new assessment tool for 
qualitative research articles. Journal of advanced nursing, 68(9), 2086-2094. https://doi.org/10.1111/j.1365-2648.2011.05898.x

Schreiber, R. S. (2001). The "how to" of grounded theory: Avoiding the pitfalls. In R. S. Schreiber, \& P. N. Stern (Eds.), Using grounded theory in nursing (pp. 55-83). New York, US: Springer.

Smith, L. (1992). Ethical issues in interviewing. Journal of Advanced Nursing, 17(1), 98-103. https://doi.org/10.1111/j.1365-2648.1992.tb01823.x

Stenius, K., Mäkelä, K., Miovský, M., \& Gabrhelík, R. (2017). How to Write Publishable Qualitative Research. In: T. F. Babor, K. Stenius, R. Pates, M. Miovský, J. O'Reilly, \& P. Candon (Eds.), A Guide for the Perplexed (p. 155-172). London, UK: Publishing Addiction Science, Ubiquity Press. https://doi.org/10.5334/bbd.h

Strauss, A., \& Corbin, J. (1998). Basics of qualitative research: Techniques and procedures for developing grounded theory (2nd ed., p. 312). Thousand Oaks, CA, US: Sage Publications.

Strauss, A., \& Corbin, J. (1990). Basics of qualitative research: Techniques and procedures for developing grounded theory (2nd ed., p. 312). Thousand Oaks, CA, US: Sage Publications.

Streubert, H., \& Carpenter, D. R. (2011). Qualitative Research in Nursing: Advancing the Humanistic Imperative (p. 470). Philadelphia, US: Lippincott Williams \& Wilkins.

Tobin, G. A., \& Begley, C. M. (2004). Methodological rigour within a qualitative framework. Journal of advanced nursing, 48(4), 388-396. https://doi.org/10.1111/j.1365-2648.2004.03207.x

\section{Copyrights}

Copyright for this article is retained by the author(s), with first publication rights granted to the journal.

This is an open-access article distributed under the terms and conditions of the Creative Commons Attribution license (http://creativecommons.org/licenses/by/4.0/). 